\title{
CARACTERIZACIÓN DEL MARCO ANTROPOLÓGICO SUBYACENTE EN LA DeClaración Universal de Derechos HuMANOS DE LA ONU DE 1948, EN RELACIÓN CON LA BIOÉTICA
} CHARACTERIZATION OF THE UNDERLYING ANTHROPOLOGICAL FRAMEWORK IN THE 1948 UNITED NATIONS UNIVERSAL DECLARATION OF HUMAN RIGHTS, IN RELATION TO BIOETHICS CARACTERIZAÇÃO DO REFERENCIAL ANTROPOLÓGICO SUBJACENTE NA DECLARAÇÃO UNIVERSAL DE DIREITOS HUMANOS DA ONU DE 1948 QUANTO À BIOÉTICA

Pedro José Sarmiento ${ }^{1}$ Gilberto A. Gamboa-Bernal ${ }^{2}$ María de los Ángeles Mazzanti² Juana Jaramillo² Nubia Posada²

\section{RESUMEN}

El presente trabajo recupera, caracteriza y evalúa el marco antropológico subyacente en la Declaración de los Derechos Humanos de 1948. Para este propósito, se utilizó como metodología el análisis del discurso y una evaluación antropológica de su contenido en relación directa con la Bioética contemporánea y sus problemas más sobresalientes.

Palabras clave: bioética, derechos humanos, antropología, derechos humanos (Fuente: DeCS, Bireme).

DOI: 10.5294/PEBI.2015.19.2.4

\section{PARA CITAR ESTE ARTíCULO / TO REFERENCE THIS ARTICLE / PARA CITAR ESTE ARTIGO}

Sarmiento PJ, Mazzanti MA, Jaramillo J, Posada N, Gamboa-Bernal GA. Caracterización del marco antropológico subyacente en la Declaración Universal de Derechos Humanos de la ONU de 1948, en relación con la bioética. pers.bioét. 2015; 19(2): 227-244. DOI: 10.5294/pebi.2015.19.2.4

1 Investigador Principal. Director Grupo Kheirón Bioética Unisabana. Universidad de La Sabana. Colombia. pedro.sarmiento@unisabana.edu.co

2 Coinvestigadores. Grupo Kheirón Bioética Unisabana. Universidad de La Sabana. Colombia.

$\begin{array}{ll}\text { FECHA DE RECEPCIÓN: } & 2015-03-04 \\ \text { FECHA DE ENVIIO A PARES: } & 2015-03-05 \\ \text { FECHA DE APROBACIÓN POR PARES: } & 2015-03-31 \\ \text { FECHA DE ACEPTACIÓN: } & 2015-05-06\end{array}$

FECHA DE RECEPCIÓN:

FECHA DE ACEPTACIÓN:
2015-05-06 


\section{Abstract}

This paper revisits, characterizes and assesses the underlying anthropological framework in the 1948 Declaration of Human Rights. Discourse analysis and an anthropological evaluation of its contents directly related to contemporary bioethics and its most outstanding problems were applied to that end.

KEYwORDs: Bioethics, human rights, anthropology, human rights (Source: DeCS, Bireme).

\section{Resumo}

O presente trabalho recupera, caracteriza e avalia o referencial antropológico subjacente na Declaração dos Direitos Humanos da ONU de 1948. Para esse propósito, utilizaram-se, como metodologia, a análise do discurso e uma avaliação antropológica de seu conteúdo em relação direta com a bioética contemporânea e seus problemas mais notáveis.

Palavras-chave: bioética, antropologia, direitos humanos (Fonte: DeCS, Bireme). 


\section{INTRODUCCIÓN}

La Declaración Universal de Derechos Humanos (DUDH) de $1948^{3}$ (1), constituye un paradigma histórico, ético, jurídico y político para el mundo, que está contenido en un marco de globalización y expansión de criterios éticos y normativos universales. En efecto, el carácter de universalidad del documento señala las directrices filosóficas, antropológicas, políticas, legislativas y de justicia de múltiples documentos y de nuevas declaraciones. ${ }^{4}$ La Declaración, proclamada a raíz de la Segunda Guerra Mundial, está compuesta por 30 artículos que, a pesar de no tener carácter vinculante, su aceptación por parte de los Estados miembros, ha recibido indiscutible reconocimiento y axiomática fuerza moral evidente en innumerables discursos políticos,

3 Este trabajo de investigación se centró en la versión oficial en español de la Declaración Universal de Derechos Humanos (DUDH) de 1948.

4 ONU. Pacto International de Derechos Económicos, Sociales y Culturales y del Pacto Internacional de Derechos Civiles y Políticos de 1966; Consejo de Europa. Convención sobre los derechos humanos y la biomedicina del Consejo de Europa de 1997; ONU. Asamblea General. Convención Internacional de las Naciones Unidas sobre la Eliminación de todas las Formas de Discriminación Racial, 1965; ONU. Asamblea General. Convención de las Naciones Unidas sobre los Derechos del Niño, 1989; ONU. Asamblea General. Normas uniformes de las Naciones Unidas sobre la igualdad de oportunidades para las personas con discapacidad de 1993; ONU. Asamblea General. Recomendación de la Unesco relativa a la situación de los investigadores científicos, 1974; ONU. Asamblea General. Convenio 169 de la OIT sobre pueblos indígenas y tribales en países independientes; La Conferencia General, Declaración Universal sobre Bioética y Derechos Humanos, 1989; ONU. Asamblea General. Tratado Internacional sobre los Recursos Fitogenéticos para la Alimentación y la Agricultura, 2001; Convenio para la protección de derechos humanos y la dignidad del ser humano con respecto a las aplicaciones de la biología y la medicina, Oviedo, 1997. documentos estatales, legislaciones diversas y múltiples citaciones y referencias de toda índole. El documento es, sin lugar a dudas, uno de los más sobresalientes puntos de referencia histórica global contemporánea en muchos órdenes. No obstante, es un hecho que algunos temas bioéticos y actividades de grupos sociales, con cierta frecuencia minoritarios, también se apoyan en apartados de este documento propiciando, como en otras circunstancias, controversia en algunas de sus interpretaciones. Tal es el caso del uso de la expresión "libre desarrollo de la personalidad" (art. 22) (1), cuyo contenido es interpretado por constituciones y sentencias de altas cortes y jueces - en formas diversas y hasta a veces contradictorias—, como se señalará a continuación.

\section{OBJETIVOS}

El principal objetivo de este trabajo, consistió en identificar el marco antropológico subyacente en la Declaración de Derechos Humanos de 1948 y determinar las relaciones intrínsecas de este documento con la Bioética, sus fortalezas y problemas fundamentales.

Para describir las características generales de dicho marco se analizaron, desde el punto de vista bioético, las tendencias ideológicas generales, las fortalezas y debilidades desde la perspectiva de su estructura y coherencia interna. Finalmente, se determinó la pertinencia del marco antropológico de la Declaración, relacionándolo con algunos de los más sobresalientes problemas bioéticos contemporáneos.

\section{MATERIALES Y MÉTODOS}

En este trabajo se utilizó la traducción oficial de la Declaración Universal de Derechos Humanos de 1948 a la lengua española (1), tomada directamente de la pá- 


\section{El "RESPETO A LAS PERSONAS Y A SU} DIGNIDAD" COMO PRINCIPIO, ES CAPAZ DE EVITAR MUCHOS ABUSOS QUE DIERON ORIGEN a la Bió́tica. Pero, sin duda, se requiere DEL CONCEPTO DE DIGNIDAD COMO BALUARTE FUNDAMENTAL DEL EJERCICIO BIOÉTICO.

gina web oficial de la ONU, dado que este documento ha servido de referencia e inspiración para personas e instituciones públicas y privadas de Iberoamérica.

Con base en la versatilidad que permite el análisis del discurso $(2,3)$, se hizo una lectura analítica del documento $(4,5)$, de la siguiente manera: 1 ) análisis textual de términos, 2) análisis de la práctica discursiva, 3) análisis de la práctica social o sociohermenéutica.

\section{MARCO TEÓRICO}

\section{La noción de dignidad y de derechos humanos}

A partir de la promulgación del documento, la noción de derechos humanos ha venido logrando transformaciones y enriquecimientos notables. Una clasificación histórica ha dividido a los derechos en tres generaciones, según su aparición cronológica, en: derechos de primera generación, que se refieren a los derechos civiles y políticos del individuo frente al Estado o cualquier autoridad. De segunda generación, que se refieren a los derechos económicos, sociales y culturales, también llamados "derechos de prestación”. Finalmente, derechos de tercera generación, que son de los pueblos, y que tienen el com- promiso de promover el progreso social y elevar el nivel de vida; son los derechos del individuo como parte de la humanidad. La expresión derechos humanos es de uso corriente en los discursos políticos y jurídicos, aunque, como se ha dicho, el contenido de los mismos pueda ser sujeto a controversia. En el marco de la Bioética y la aplicación práctica de los contenidos de la Carta, existen varios problemas en relación con el vínculo que une la Bioética con los derechos humanos. Sobre este punto se evidencia que, por un lado, se afronta una tácita relación entre los derechos y la noción de dignidad, hecho de graves consecuencias, tal y como señala Habermas (6), en el caso de amenazas directas contra el contenido de la dignidad, representadas en algunas interpretaciones que han osado referirse al concepto de dignidad como superfluo y vacío (7). El análisis de las consecuencias de este problema en el marco de la Bioética, es verdaderamente necesario. En efecto, si la Bioética aspira a proteger los valores que se propuso desde su origen, es necesario que el contenido del concepto de dignidad humana sea unívoco, explícito e inherente a todos los individuos de nuestra especie, sin distinción alguna, y que a su vez, esté ligado intrínsecamente a la noción de derecho presente en la Carta de los derechos humanos. $\mathrm{El}$ "respeto a las personas y a su dignidad" como principio, es capaz de evitar muchos abusos que dieron origen a la Bioética. Pero, sin duda, se requiere del concepto de dignidad como baluarte fundamental del ejercicio bioético $(8,9)$. Los principios que constituyen los ejes de los sistemas de protección en cualquier escenario jurídico, incluso de otras declaraciones que siguieron a la de 1948, son la dignidad del ser humano, la libertad y la igualdad, de los que se derivan el principio de universalidad en la aplicación de los derechos humanos, y su carácter absoluto e inalienable. Existe otro principio esencial que se apoya en el artículo 30, y manifiesta la 
indivisibilidad de los derechos humanos, en el sentido de no considerar que exista una jerarquía entre ellos sino que, más bien, todos los derechos puedan ser vistos e interpretados como interdependientes. La presencia de estos problemas hermenéuticos y sociojurídicos, contribuyó a justificar la importancia de determinar el marco antropológico presente en la Declaración Universal de los Derechos Humanos, de forma tal que se pueda captar adecuadamente su espíritu y también corregir desviaciones e interpretaciones inadecuadas o abusivas.

\section{Análisis del discurso}

El análisis del discurso es una metodología que resulta de la confluencia de distintas perspectivas sobre fenómenos significantes. Entre las visiones filosóficas más célebres sobre el análisis del discurso está la perspectiva arqueológica introducida por Michel Foucault, quien desplazó el interés de la historia de las ideas al campo de los dispositivos de enunciación, en un sentido diferente al de la lingüística. Con base en un nuevo aparato conceptual que incluye conceptos como formación discursiva, práctica discursiva, dispositivo y sistema de dispersión, Foucault desarrolló una metodología para reconstruir las ciencias, los discursos y los conceptos develando sus orígenes y encadenando su historia con el momento (10).

El discurso es una categoría de análisis que posibilita una forma amplia de entender cómo las ideas guían las acciones sociales y operan en las instituciones. La perspectiva del análisis del discurso sostenida por Michel Foucault permite un acercamiento que devela el sentido, los propósitos y el deseo del discurso, su organización y jerarquización (11). Este enfoque, además, cuestiona la importancia de los discursos en la realidad social, devela la intencionalidad y las ideas presentes tras los enunciados.

Las interpretaciones problemáticas. Uno de los casos más célebres de interpretaciones problemáticas desde el punto de vista bioético y jurídico está representado por la respuesta de la Comisión Interamericana de Derechos Humanos (CIDH) el 29 de julio de 2011, corporación jurídica a la que llegó el caso de dieciocho personas que demandaron al Estado costarricense por violación “de los derechos a la vida privada y familiar, del derecho a fundar una familia y del derecho a la igualdad y no discriminación”, consagrados en los artículos 11, 17 y 24 de la Convención Americana sobre Derechos Humanos, en relación con los artículos 1.1 y 2 del mismo documento. Estas violaciones, según los demandantes, ocurrieron como consecuencia de la prohibición general de practicar la fecundación in vitro, proscripción que ha estado vigente en Costa Rica desde el año 2000, tras una decisión emitida por la Sala Constitucional de la Corte Suprema de Justicia de dicho país. Como se indica en el informe de fondo 85/10 (12), la comisión encargada del caso consideró que esta prohibición absoluta constituyó una injerencia arbitraria en los derechos a la vida privada y familiar, y a formar una familia. Asimismo, esta comisión consideró que la prohibición constituyó una "violación del derecho a la igualdad de las víctimas”, en tanto que el Estado les impidió el acceso a un tratamiento que les hubiera permitido superar su situación de desventaja respecto de la posibilidad de tener hijos biológicos. Este impedimento tuvo, además, según la comisión, “un impacto desproporcionado en las mujeres".

Ante tal circunstancia, el Estado de Costa Rica respondió a la demanda apelando a la necesidad de protección del derecho a la vida, cuando señaló: 
El Estado sostiene que los hechos del caso no caracterizan violación a los derechos humanos garantizados por la Convención Americana y, por ende, no ha cometido violación de dicho instrumento. El Estado indica que la Sala Constitucional reguló el derecho relativo a procrear indicando que debe ser subordinado al derecho absoluto a la vida porque sería contradictorio aceptar la posibilidad de una vida a costa de la pérdida de otras vidas humanas, lo cual, en su consideración, sucede con la técnica de la fecundación in vitro. Con ello, el Estado sostiene que Costa Rica no hace más que aplicar el artículo 4 de la Convención Americana (12).

Tanto los demandantes como el Estado de Costa Rica defendieron sus posiciones con argumentos de la Convención Americana sobre Derechos Humanos, que se apoyan y fundamentan en la Carta Magna de Derechos Humanos de 1948. Los derechos a la vida privada y familiar, a fundar una familia, a la igualdad y no discriminación y a la vida consagrados en los artículos 10, 12, 16, 23 y 3, respectivamente, de la Carta Magna, fueron utilizados de manera simultánea para defender posiciones contrarias. En efecto, en el caso señalado, puede concluirse que la argumentación y proposición de ambas partes surge de las diversas interpretaciones que se hacen sobre el contenido del articulado. Si se examina esta circunstancia detalladamente, se observa que el manejo que se da por parte de los demandantes no tiene en cuenta la preponderancia del artículo fundamental de "derecho a la vida", sino que le da mayor importancia a los otros artículos que dependen de este. El resultado práctico de esta confrontación derivó en que, finalmente, el Estado de Costa Rica perdió en este debate y, en consecuencia, debió incluir dentro del gasto público en salud atender con la fecundación in vitro a todas las parejas que lo lleguen a necesitar.

Otro caso que demuestra esta problemática hermenéutica está representado en la sentencia C-577 de 2011, de la Corte Constitucional, por la cual se propuso un proyecto de ley estatutaria, con control previo de la Corte, para legislar sobre la reglamentación de las uniones civiles entre parejas del mismo sexo. Con esta sentencia se pretende incluso reformar los artículos del Código Civil colombiano que hacen referencia al matrimonio. Esta sentencia implica un cambio en el contenido del artículo 113 de esa norma, en la cual se afirma que el matrimonio "es un contrato solemne por el cual un hombre y una mujer se unen con el fin de vivir juntos, de procrear y de auxiliarse mutuamente" (art. 113) (13). La propuesta de reforma significaría un cambio sustancial cuyo resultado sería: "El matrimonio es un contrato solemne por el cual dos personas hacen una comunidad de vida permanente y singular, con el fin de convivir y auxiliarse mutuamente" (14). Puede observarse que en esta iniciativa se excluyen los términos "un hombre y una mujer", lo mismo que se omite la expresión "procrear"; simplemente por "dos personas" admitiendo que puedan ser del mismo sexo.

La Carta Magna de Derechos Humanos de 1948, en el artículo 16, señala que "Los hombres y las mujeres, a partir de la edad núbil, tienen derecho, sin restricción alguna por motivos de raza, nacionalidad o religión, a casarse y fundar una familia, y [que] disfrutarán de iguales derechos en cuanto al matrimonio, durante el matrimonio y en caso de disolución de matrimonio" (art. 4) (1). En la propuesta de modificación del artículo mencionado se expone, según los demandantes, que la 
Carta no está haciendo alusión exclusiva a las parejas heterosexuales y que, por tanto, estarían en posibilidad de gozar de estos derechos las parejas homosexuales. Esta afirmación también parece desconocer las raíces culturales y sociológicas de la Declaración basadas en la concepción de matrimonio natural, entre un hombre y una mujer. Los ponentes de la reforma afirman que "de la Declaración Universal de Derechos Humanos (DUDH) también se puede entender que 'los hombres y las mujeres' —entiéndanse por estos los hombres y mujeres homosexuales o heterosexuales-, a partir de la edad núbil, tienen derecho, sin restricción alguna (en este caso por orientación sexual) a casarse y fundar una familia" (art. 16) (1). Asimismo, los movimientos homosexuales se apoyan en el artículo 2 de la Declaración, según el cual, "Toda persona tiene todos los derechos y libertades proclamados en esta declaración, sin distinción alguna de raza, color, sexo, idioma [...] o de cualquier índole, origen nacional o social [...] o cualquier otra condición", para exigir el derecho al matrimonio civil, indicando que no se le puede negar a personas homosexuales. Otro argumento que se añade, consiste en asumir que el derecho del hombre y de la mujer a contraer matrimonio se puede aplicar a los hombres y las mujeres homosexuales, simplemente porque son personas. En consecuencia, tendrían el derecho a constituir una familia como lo dice la Declaración en el artículo 16. Esta muestra de hechos relativos a la aplicación de los contenidos y espíritu del documento, manifiestan la necesidad de determinar el marco antropológico subyacente de forma que pueda lograrse una adecuada comprensión de su contenido general, de su espíritu y de su auténtico alcance. La importancia de este contenido se hace también importante si se quiere dar luz al debate público y bioético específico de nuestros días en algunos otros variados temas puntales y controversiales.

\section{ANÁLISIS Y RESULTADOS}

Categorías antropológicas generales utilizadas como criterio de búsqueda en la Declaración Universal de Derechos Humanos de 1948

Mediante una lectura analítica de los términos y unidades de sentido de todo el documento, se clasificaron, en un primer momento, las siguientes categorías antropológicas generales: a) ser, b) persona, c) individuo y d) humano, las mismas que fueron elegidas como elementos comunes a todo conocimiento sobre el hombre, con independencia de discursos o posicionamientos filosóficos específicos. Se comprendieron estas categorías bajo los siguientes criterios:

\section{a) Categoría "ser"}

"Ser" es un concepto fundamental de la filosofía, que se emplea con un sentido técnico y ha recibido multitud de acepciones a lo largo de la historia. Para Aristóteles, el "ser" es aquello más común y general que comparten todas las entidades y cuyos rasgos son universales. Para este filósofo, el análisis de lo que es el ser, constituye la ocupación central de la filosofía. El objeto de la filosofía y, en particular, de la metafísica es, precisamente, analizar el ser. Debe distinguirse del carácter concreto que poseen las entidades, así como de la existencia, ya que el ser es más que la existencia. Una de las posibilidades de ser, que permite automovimiento o animación, individuación, unidad, crecimiento, desarrollo, procreación y muerte, es el fenómeno reconocido con el nombre de "vida". Ens, es la afirmación fundamental de la cosa en el ser, en virtud de la cual algo se constituye como real por contraposición a posible. 
Como ens significa que algo propiamente existe en acto, y el acto tiene un orden a la potencia, se dice que una cosa es absolutamente (simple ens) en cuanto que primariamente se distingue de lo que solo está en potencia. Y este es el ser sustancial de una cosa cualquiera. De modo que una cosa se dice ens simpliciter por su ser sustancial (15).

El uso del concepto y vocablo "ser" en el lenguaje corriente es imprescindible. De esta noción se derivan las categorías que se abordan a continuación.

\section{b) Categoría persona}

La categoría de persona se refiere, de forma específica, a la singularización de un acto de ser en un sujeto vivo dotado de entendimiento y voluntad, dimensiones que, en el marco de la libertad natural e intrínsecamente propia, le hacen responsable de sus decisiones, es decir, un "ser ético". A este contenido se añaden manifestaciones relativas a su racionalidad propia, visible en la capacidad de captar la realidad y crear otras propiamente suyas - como el derecho - en armonía con conceptos, símbolos y abstracciones. Otras dimensiones de la persona se refieren a su identidad exclusiva, la presencia y ordenamiento de su vida social e individual en el marco de los derechos, su individualidad, su espiritualidad y otras realidades que lo caracterizan tales como la autoconciencia, la condición de apertura, la interioridad, la vida social y de comunidad, lo mismo que vida de familia y relaciones interpersonales de afecto, amistad y amor. Esta categoría incluye la intrínseca dignidad de la persona y todas las consecuencias derivadas de ella, frecuentemente vinculadas con la ética y el derecho. Puede añadirse que "la persona no es un algo creado, cualitativamente descriptible, una naturaleza orgánica, etc., sino que la persona es alguien. Efectivamente, aquel alguien que me contempla desde un rostro humano y sobre quien no puedo disponer nunca como de una cosa" (13).

c) Categoría individuo

Categoría que contiene todo elemento común como miembro de una especie biológica, por ejemplo, la alimentación, la asociación, el comportamiento y la cooperación, etc.

d) Categoría humano

La categoría de "humano" contiene, de modo genérico, toda expresión perteneciente al homo sapiens que, como rasgo sobresaliente, manifiesta una corporalidad, una genética y una racionalidad específicas, íntimamente unidas. Tal condición lo hace capaz de conocer y realizar operaciones conceptuales simbólicas complejas, en el marco de un sistema lingüístico común, al igual que otras acciones exclusivamente humanas como la introspección, la religiosidad, el arte, la especulación filosófica y la historicidad, entre otras muchas otras. Todo lo anterior ha posibilitado la vida en comunidad y la conformación de las bases culturales en diferentes grados de desarrollo. Algunos ejemplos de esta categoría son las artes, la educación y las manifestaciones culturales diversas.

En un segundo momento, mediante el análisis de cinco bioeticistas, se recuperaron todas las unidades conceptuales de sentido y se clasificaron en cascada dentro de estas categorías, utilizando una matriz de Excel, que incluyó cada unidad dentro de la categoría correspon- 
diente. Posteriormente, estas unidades de sentido de cada categoría se subclasificaron dentro de componentes esenciales, existenciales y cualidades esenciales y existenciales, respectivamente. El criterio de subclasificación se hizo con base en las siguientes definiciones:

\section{Componente (elemento) esencial: es una noción} que pertenece a la naturaleza de todos los miembros de la categoría de que se trate y hace referencia a realidades universales, intrínsecas, inalienables e intangibles (p. ej., conciencia, creencia, deberes, dignidad, etc.).

2. Componente (situación) existencial: es una situación que incluye acciones, condiciones de vida, implicaciones de relación con los otros y el medio, con carácter contingente (p. ej., ser acusado, ser condenado, consentir, etc.).

3. Cualidad esencial: es una noción que incluye características naturales o adquiridas y hábitos operativos (virtudes o vicios) que afectan la naturaleza humana (p. ej., ser cruel, tener compromiso, esforzarse, ser justo, etc.).

4. Cualidad existencial: es una característica natural o adquirida contingente (p. ej., bienestar, pacífico, satisfactorio).

Considerando que los componentes esenciales son la raíz tanto de los componentes existenciales como de las cualidades esenciales y existenciales de las tres categorías, persona, humano e individuo, se tomaron como eje de análisis primario los componentes esenciales y se distribuyeron dentro de las siguientes dimensiones antropológicas universales: física, psicológica-mental-afectiva, espiritual y, social y trascendente. Estas dimensiones fueron concebidas de la siguiente manera:

1. Dimensión física: incluye todo lo relativo a la corporalidad biológica humana.

2. Dimensión psicológica-mental-afectiva: comprende todas las manifestaciones de las facultades mentales superiores y afectivas, conscientes e inconscientes del ser humano. En esta dimensión se incluyen también la intimidad y el amor.

3. Dimensión espiritual: comprende todas las realidades inmateriales del ser humano relativas a su vida moral (autonomía, libertad y dignidad), y a su mundo subjetivo (conciencia, creencias e intimidad), al igual que expresiones auténticamente humanas como el derecho, el arte y el pensamiento.

4. Dimensión social y trascendente (o intersubjetiva): constituye la dimensión que relaciona a los seres humanos entre sí, en unidades fundamentales tales como la familia, el matrimonio y la noción de comunidad en la perspectiva del bien común. Esta dimensión incluye la capacidad del respeto como virtud, y de la responsabilidad.

5. Elementos transversales (a las anteriores dimensiones): son aquellos elementos que muestran la unidad sustancial de todas las anteriores dimensiones en el ser humano, entre las que se incluyen la capacidad de donación, la capacidad de dar sentido a las acciones y la existencia, y la intimidad.

\section{Resultados del análisis textual del documento}

La recuperación y clasificación de las unidades de sentido se hizo a partir de la búsqueda, en el texto de la versión 
española de la Declaración de 1948, de las expresiones "Persona", "Individuo" y "Humano". El documento se refiere de forma indeterminada como "nadie", "a nadie" y "todos", en nueve ocasiones, en los artículos 4, 5, 7, 9, $11 b, 12,17$ y 20 . Se entiende que la forma indeterminada "todos", por ejemplo, "Todos son iguales ante la ley y tienen, sin distinción, derecho a igual protección de la ley", o "Todos tienen derecho a igual protección contra toda discriminación que infrinja esta Declaración y contra toda provocación a tal discriminación" (art. 7) y "Nadie será sometido a torturas ni a penas o tratos crueles, inhumanos o degradantes" (art. 5), se trata de una forma gramatical genérica "nadie", expresión que naturalmente incluye al ser humano y que, a su vez, incluye a la persona, la que, sucesivamente a su vez, también incluye al varón y la mujer.

La expresión —en la versión española-individuo, es usada en el texto también de forma indistinta como persona o humano. ${ }^{5}$ Este término se usa en dos ocasiones, en los artículos 3 y 19: "Todo individuo tiene derecho a la vida, a la libertad y a la seguridad de su persona" (art. 3), y "Todo individuo tiene derecho a la libertad de opinión y de expresión; este derecho incluye el de no ser molestado a causa de sus opiniones, el de investigar y recibir informaciones y opiniones, y el de difundirlas, sin limitación de fronteras, por cualquier medio de expresión" (art. 19). El término individuo, usado de forma genérica, propone que el sujeto debe ser protegido por un régimen de derecho: "Considerando esencial que los derechos humanos sean protegidos por un régimen de derecho, a fin de que el hombre no se vea

5 La versión española del documento hace uso del término "individuo", como traducción de la expresión everyone. compelido al supremo recurso de la rebelión contra la tiranía y la opresión” (1).

La expresión persona se usa en 31 ocasiones en todo el texto (ver articulado y considerandos), y especialmente en los artículos 2, 3, 4, 8, 11, 13, 15, 17, 18, y del 20 al 29. La expresión hombre, utilizada de forma genérica, es empleada en seis ocasiones (ver considerandos, párrafos segundo, tercero, quinto y sexto y en el artículo 16) ${ }^{6}$. La expresión "hombres y mujeres" se usa en dos ocasiones: en el Preámbulo y en el artículo 16 (Sobre el derecho a casarse y fundar una familia). Llama la atención la referencia a la mujer: considerada de forma exclusiva, no existe dentro del texto. La expresión "ser humano" o "seres humanos", solo aparece citada dos veces (Preámbulo, párrafo segundo 2 y artículo 1).

\section{Resultados del análisis textual de términos}

Las unidades de sentido obtenidas en las categorías de: a) persona, b) individuo y c) humano, fueron nuevamente clasificadas como "componente esencial", "componente existencial", "cualidad esencial" y "cualidad existencial". Luego de la criba general practicada, se encontró que el documento incluye 266 expresiones relativas a la persona, el individuo y lo humano, que se distribuyen en las siguientes proporciones numéricas: elementos relativos a la categoría persona: $33,9 \%$; elementos relativos a la categoría individuo: $25,9 \%$ elementos relativos a la categoría humano: 40,2\%.

6 La primera acepción de vocablo hombre en el diccionario de la Real Academia de la Lengua es "1. m. Ser animado racional, varón o mujer”. De donde se infiere que el vocablo incluye tanto al varón como a la mujer. 


\section{EXISTE UnA NOTABLE DifERENCIA entre REFERIRSE A "INDIVIDUOS" y A "PERSONAS", EN TANTO QUE EL INDIVIDUO PUEDE SER CONSIDERADO COMO UN ELEMENTO QUE HACE PARTE DE UNA COMUNIDAD, EN GENERAL, DE SERES BIOLÓGICOS.}

Atendiendo a estos resultados, podría inferirse que el documento, en general, manifiesta una aceptable consistencia entre el título y el contenido. Evidentemente, se trata de derechos humanos en todo el sentido de su expresión, comprendidos como el orden normativo e institucional de la conducta humana en sociedad que se inspira en postulados de justicia y en la dignidad personal. Se evidencia una relativa proporción entre los elementos personales, individuales y humanos, dando prevalencia ligeramente superior a los aspectos humanos antes que a los personales e individuales.

Es llamativo que más de una cuarta parte de los elementos hagan referencia al individuo (según la versión oficial en español), especialmente si se considera que el documento trata de la especie humana y no de otra categoría de individuos de naturaleza biológica. En consecuencia, podría inferirse que la Declaración, en la versión española, podría estar afianzada en un enfoque de carácter biológico, incluso "biologista". Sin embargo, la versión oficial del documento en inglés usa la expresión everybody, cuyo significado hace referencia a "personas" en oposición a "individuos", de la versión en español, término que evoca más a sujetos biológicos que a seres humanos. Conviene señalar que este hecho (dependiente del trasfondo semántico de la expresión individuo en oposición a persona como traducción de everybody), desde el punto de vista bioético, tiene serias implicaciones hermenéuticas, especialmente cuando se utilizan partes del documento para redactar políticas nacionales o internacionales, tal y como se ha comentado. No cabe duda de que existe una notable diferencia entre referirse a "individuos" y a "personas", en tanto que el individuo puede ser considerado como un elemento que hace parte de una comunidad, en general, de seres biológicos. En oposición a este concepto, la expresión "persona" se refiere al sujeto de la especie humana cuyos derechos han sido reconocidos desde hace décadas y que son consagrados de forma solemne en la Carta.

\section{Análisis antropológico en relación con los elementos clasificados}

A continuación se relacionan las proporciones de los componentes esenciales, cualidades esenciales, cualidades existenciales y componentes existenciales presentes en el documento: 1) se evidencia una importante desproporción entre los componentes esenciales y existenciales, y las cualidades esenciales y existenciales. En efecto, la evaluación de esta proporción demostró que el 80,8\% gravita en elementos existenciales, mientras que lo esencial, representado como cualidades y componentes "esenciales", es decir, que hacen parte de la "esencia humana" (por ejemplo, conciencia, creencia, deberes, dignidad, ser justo, ser cruel, tener compromiso, esforzarse) se reduce al 19,2\%.2) De lo anterior podría deducirse que la Carta privilegia aspectos de carácter existencial o contingente, tales como "ser sujeto de 
mérito", capacidad para la "amistad", o para "consentir", y hechos contingentes tales como "ser acusado", "ser objeto de torturas o tratos crueles", etc. 3) Esta proporción se comprende en el contexto en que el componente existencial es mucho más variado, amplio y pluriforme que el esencial. No obstante, al examinar los componentes esenciales se evidencia la ausencia de algunos componentes clave, tales como "respeto", "responsabilidad", "afectividad", con lo cual se puede pensar que el documento pudo pasar por alto el fortalecimiento de los derechos humanos con componentes esenciales.

\section{Análisis en función de componentes esenciales}

En el análisis efectuado, se evidencia que dentro de los componentes esenciales existen notables fortalezas en el documento, derivadas del predominio de lo personal sobre lo individual y humano. Cualquier antropología admitiría el carácter esencial de estos componentes. De los trece elementos de la persona subrayamos seis de ellos por su particular importancia antropológica: 1) la dignidad, 2) la libertad, 3) la razón, 4) la voluntad, 5) la conciencia y 6) la familia; todo lo cual contribuye a reconocer el valor elevado de la Declaración como inspiración y orientación de muchos documentos, siempre y cuando no se pierda la preeminencia jerárquica de lo personal sobre lo individual y lo humano, y se garantice un significado unívoco para dichos elementos. En la categoría de individuo, están presentes elementos comunes a otras especies, en ocasiones relacionadas con el individuo, considerado singularmente; en otras, considerado como parte de una colectividad, en cuanto que es un ser social. Por ejemplo: "alimentación”, "colectiva", "común", "comunidad", "desarrollo", "edad” e "independiente”. La presencia de estos elementos se evidencia como sobresaliente, pues, en contraposición a una lectura individualista del documento, se encuentran elementos de esta categoría donde se manifiesta la irrenunciable naturaleza social y familiar del individuo. El documento, además, contiene conceptos individuales que hacen referencia al origen, tales como "nacer", "padres", "alimentación", "desarrollo", comunes a otras especies pero radicalmente importantes para el ser humano y vinculadas estrechamente con su dignidad. El equipo de los cinco bioeticistas encontró que hay elementos que pueden complementar el marco antropológico de manera importante. La presencia de la afectividad, la trascendencia, la intimidad, la espiritualidad, el amor, la corporalidad y la capacidad de dar sentido, son elementos antropológicos sustanciales que enriquecen el cuadro.

\section{Resultados del análisis de la práctica discursiva}

Del análisis de la práctica discursiva $(6,7,16,17)$ se determinaron las siguientes categorías: la primera se refiere al orden escogido por los autores de la Declaración para manifestar secuencialmente los conceptos. Se redactó un Preámbulo con consideraciones esenciales para fundamentar la "Declaración" de treinta artículos que contienen los derechos humanos que se derivan de dicho preámbulo.

La segunda categoría seleccionada fue el contenido mismo del Preámbulo. Este apartado consta de siete párrafos, simbolizados por las expresiones "Considerando que..." y "Considerando esencial que...", afirmaciones que se presentan en la declaración "como ideal común por el que todos los pueblos y naciones deben esforzarse". La secuencia de considerandos invita a asignarle un valor o un peso importante a algunos aspectos a fin de puntualizar y entrelazar conceptos y motivos para fundamentar los artículos. La práctica discursiva de los considerandos 
contiene descripciones sobre las consecuencias del reconocimiento o no de la dignidad intrínseca de los seres humanos. Cuando se reconoce la dignidad pueden garantizarse los derechos que contiene la Carta. Por el contrario, cuando se omite la consideración de la dignidad como realidad humana, la posibilidad de amenazas es evidente, tal y como señalan los apartados del preámbulo. La tercera categoría elegida determinó la ordenación de los artículos. A continuación se describen las tres categorías analizadas:

\section{Primera categoría: orden de secuencia de conceptos}

ralmente, es la condición de posibilidad de la libertad, la justicia y la paz. En otras palabras, no hay libertad, ni justicia, ni paz, en ausencia del reconocimiento de esta dignidad intrínseca humana. Esta afirmación, enunciada en el primero de los párrafos del documento, hace depender todo lo afirmado de la noción de "dignidad intrínseca” del ser humano. Este hecho contiene un trascendental significado, en la medida en que le da una estructura antropológica fundamental y "esencial" al documento. Para la bioética es una piedra de toque en tanto todo su trabajo depende esencialmente de este reconocimiento.
El documento es enfático en afirmar que la base para "la libertad, la justicia y la paz en el mundo", que promueva "el desarrollo de las relaciones amistosas entre las naciones" " "la aspiración más elevada del hombre", para que "disfruten de la libertad de palabra y de la libertad de creencias", tiene "por base el reconocimiento de la dignidad intrínseca y de los derechos iguales e inalienables de todos los miembros de la familia humana". La libertad es el primero de los conceptos considerados en el Preámbulo. Le siguen la justicia y la paz. Tales conceptos están vinculados a una condición esencial dentro del documento: el reconocimiento de la dignidad intrínseca y de los derechos iguales e inalienables de todos los miembros de la familia humana. Con esta afirmación se declara que los más importantes conceptos que pretende defender y promulgar el documento, dependen en exclusivo, del reconocimiento de la dignidad intrínseca de los seres humanos. La "dignidad intrínseca", así enunciada lite-
A continuación de este eje conceptual, que se convierte en la condición de posibilidad de la libertad, la justicia y la paz, denuncia que "el desconocimiento y el menosprecio de los derechos humanos han originado actos de barbarie ultrajantes para la conciencia de la humanidad", y muestra que es necesario liberar a la humanidad "del temor y de la miseria”. Este segundo lugar, después del reconocimiento de la dignidad, implica que su desconocimiento genera - y generó- actos que son indeseables para el hombre. Frente a los abusos contra los derechos humanos el documento plantea la necesidad de encontrar una solución que garantice su protección mediante "un régimen de Derecho".

\section{Segunda categoría: contenido del preámbulo}

Los siete considerandos del documento manifiestan, de una parte, las mayores aspiraciones sociales estrecha- 
mente ligadas con una realidad antropológica esencial: la dignidad intrínseca humana y las consecuencias del menosprecio o desconocimiento de los derechos derivados de la misma. Hay una referencia de consenso en la redacción del documento cuando señala que "los pueblos de las Naciones Unidas han reafirmado en la Carta su fe en los derechos fundamentales del hombre, en la dignidad y el valor de la persona humana, y en la igualdad de derechos de hombres y mujeres". Este hecho de consenso implica un reforzamiento del primer reconocimiento, ahora soportado por la unanimidad, lo que hace aún más indiscutible el contenido de estos presupuestos. Finaliza el Preámbulo con los compromisos de los Estados miembros, cuando considera que se deben dedicar, de modo "universal y efectivo", a respetar "los derechos y libertades fundamentales" y a "promover el progreso social y a elevar el nivel de vida dentro de un concepto más amplio de la libertad". Este logro depende de la "concepción común" de los considerandos, de su apropiación como "inspiración" y de su puesta en práctica "mediante la enseñanza y la educación”. Dado que la inspiración y la enseñanza pueden no ser la única solución para evitar abusos, el documento invita a implicar a los Estados miembros a que "aseguren, por medidas progresivas de carácter nacional e internacional, su reconocimiento y aplicación universales y efectivos, tanto entre los pueblos de los Estados miembros como entre los de los territorios colocados bajo su jurisdicción”.

\section{Tercera categoría: organización de los artículos}

La tercera categoría, que examina la organización de los artículos, manifiesta tres elementos de consideración. Primero, se evidencia que la secuencia numérica, desde el artículo 1 hasta el artículo 30, es coherente con el contenido del Preámbulo. No se evidencian rupturas de sentido ni incoherencias temáticas. Segundo, se evidencia de forma taxativa que el corazón de la Declaración es "el reconocimiento de la dignidad intrínseca y de los derechos iguales e inalienables de todos los miembros de la familia humana". Este hecho, absolutamente relevante en su momento (y sin duda alguna, para nuestro tiempo), constituye el eje vertebral del documento. Tercero, a partir de la base de la dignidad intrínseca y de los derechos inalienables de todos los miembros de la familia humana, los derechos humanos presentes en todo el documento se van entrelazando y apoyando uno con otro, de forma tal que no puede interpretarse ninguno al margen de este reconocimiento. Finalmente, con el artículo 30, la Declaración cierra su discurso con una prohibición explícita: “Nada en esta Declaración podrá interpretarse en el sentido de que confiere derecho alguno al Estado, a un grupo o a una persona, para emprender y desarrollar actividades o realizar actos tendientes a la supresión de cualquiera de los derechos y libertades proclamados en esta Declaración”. Esta indicación es vital en la medida en que enseña y enfatiza que todos los artículos están interrelacionados, que tienen idéntico valor y universalidad, y subraya que, todo Estado, grupo o persona deberá asumirlos como propios, todos en su conjunto y cada uno. La organización del Preámbulo en sus considerandos pretende explícitamente aunar los derechos humanos alrededor de la base, de la dignidad intrínseca de todo ser humano por el hecho de pertenecer a la gran familia humana. Los contenidos giran alrededor del concepto fundamental, de forma que el discurso va emergiendo como una espiral que vuelve una y otra vez sobre el eje de la dignidad fundamental de la persona humana, y no lo pierde nunca de vista. De esto se deriva que todos los artículos deben ser leídos con la premisa esencial, eje de todo el documento, enunciada como "la 


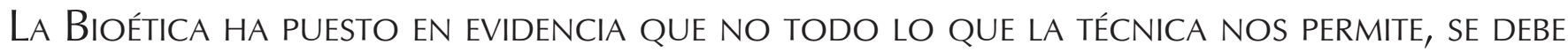

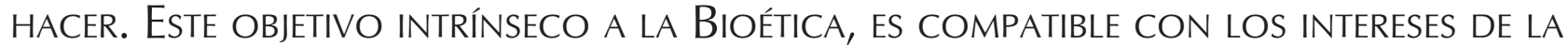 Carta, al seÑalar que tanto la Dignidad del SER humano COMO SU PROPIA VIDA PUEDEN SER VULNERADAS EN SUS DERECHOS FUNDAMENTALES.}

dignidad intrínseca del ser humano", a partir de la cual se derivan los "derechos iguales e inalienables", "de la familia humana”. El ejercicio hermenéutico discursivo sobre el documento, pone en evidencia que se trata de una "familia humana" vulnerable, que necesita ser protegida por la expresión de sus derechos y que necesita tutelar sus bienes y respaldarlos con el derecho. Es la propia "familia humana", que puede volverse enemiga de sí misma, como lo manifiesta el "Preámbulo", una de las amenazas ante las cuales la Carta pretende asegurar y garantizar un fuerte conceptual específico.

Como resultado del análisis expuesto hasta ahora, se evidencia una estructura antropológica auténticamente visible: se trata de una declaración de derechos de la persona, que posee una dignidad intrínseca, que hace parte de una familia humana y que está en particulares condiciones de vulnerabilidad respecto a sus derechos fundamentales como los derechos a la vida, a la libertad, a la expresión, a la libertad de pensamiento, a la libertad de conciencia, de religión, de opinión, derechos todos relacionados de forma directa e indirecta con la Bioética y sus problemas fundamentales. En este sentido, es necesario señalar cómo la técnica que, aunque ha ensanchado de forma extraordinaria el campo de acción y, con ello, las posibilidades de tanto de beneficio, también ha sido ocasión de abuso contra el ser humano, al mismo tiempo que de nuevos interrogantes. Esta circunstancia de ambivalencia de la tecnociencia se convierte en un factor determinante en los análisis relativos a las posibles violaciones de los derechos humanos consagrados dentro del documento. En efecto, la Bioética ha puesto en evidencia que no todo lo que la técnica nos permite, se debe hacer. Este objetivo intrínseco a la Bioética, es compatible con los intereses de la Carta, al señalar que tanto la dignidad del ser humano como su propia vida pueden ser vulneradas en sus derechos fundamentales. Tal hecho manifiesta la relación estrecha entre la Bioética y la Carta como documento social y político.

Tanto los considerandos como las afirmaciones, declaraciones explícitas o manifestaciones de intención del documento generalmente se presentan numeradas. Esto hace pensar en una secuencia o en una jerarquía. No obstante, una lectura de conjunto evidencia una estructura monolítica de derechos que gravitan alrededor de la noción de dignidad de la persona humana, elemento del que deriva el conjunto de todos los derechos expresados dentro del documento. Como se afirmó, los derechos humanos son derechos en cuanto que cada uno es fundamental para cada individuo y grupo humano. El artículo 30 se muestra como la vía de aseguramiento en las interpretaciones parciales, subjetivas o aisladas que pueda hacerse del documento. La estructura conceptual de la Carta es de absoluta unidad e interdependencia. Esto significa 
que si se elimina uno solo de los artículos precedentes, de alguna manera todos se verán violentados.

\section{CONCLUSIONES}

En líneas generales, el marco antropológico del texto, por sus contenidos, se evidencia compatible con la multiculturalidad, la diversidad de credos y, sin duda alguna, con los objetivos esenciales de la Bioética. Pese a las duras críticas a la ilustración y al liberalismo, y el paso a un pensamiento contemporáneo más fragmentado, los derechos humanos aún son legítimos como proyecto político, social y ético; no importa si se es "de izquierda" o "de derecha", creyente, agnóstico o ateo. Es auténticamente visible e incuestionable que lo propio de esos derechos es asegurar "el reconocimiento de la dignidad intrínseca y de los derechos iguales de todos los miembros de la familia humana" (1); estos elementos consolidan una estructura antropológica fuerte como realidades connaturales a su ser. Al mencionar la "dignidad" se usa el calificativo de "intrínseca" con lo cual se resalta la esencia de los contenidos antropológicos más elevados de la persona, invariables en cualquier circunstancia e iguales para todo ser humano, cualquiera que sea su condición, estado de desarrollo o condición física. A pesar de que la naturaleza intrínseca de la dignidad haya sido objeto de críticas, especialmente en el terreno del derecho positivo, esta perspectiva se reconoce como el eje más importante del documento cuyo contenido permea, articula y condiciona todos los derechos reconocidos para el género humano. Tal presupuesto tiene absoluta pertinencia y relación con el ejercicio práctico de la Bioética contemporánea y sus principales problemas, lo mismo que permite una invocación de sus objetivos de protección ante la vulnerabilidad del ser humano, también reconocida dentro del documento como real y presente. A su vez, la noción de dignidad presente en todo el documento le da unidad y cohesión. Ni un solo artículo — según la advertencia consagrada en el artículo 30 - , puede ser interpretado al margen de este concepto que, a su vez, fundamenta la ética y hace parte del ejercicio de la Bioética. De otra parte, la presencia explícita de estos derechos hace visibles contenidos bioéticos y sociales igualmente universales. Todos los derechos, tales como el derecho a la vida, al trabajo etc., están fundados en la dignidad del ser humano y se aplican por igual a todos los miembros de la familia humana sin ninguna distinción. A pesar del enfoque centrado en aspectos existenciales, la mención de la familia humana como expresión — sin el uso del término "especie" en sentido biológico- ofrece un significado adicional a los derechos y al contexto antropológico de la misma.

Aunque el documento no hace ninguna mención a los derechos particulares de la mujer, se entiende que en todas sus expresiones está incluida como parte de la familia humana y no encuentra necesaria ninguna otra explicitación que ideologías de género han cuestionado como discriminatorias en los últimos años. La ausencia del vocablo "mujer" en el texto de la Declaración hace evidente que en 1948, todavía la ideología de género no estaba presente en los escenarios internacionales; implícitamente estaba reconocido que la utilización del sustantivo "hombre" llevaba sobrentendido tanto al varón como a la mujer, a la persona masculina como a la persona femenina. Solo en el Preámbulo se menciona a las "mujeres" para resaltar la igualdad de derechos con los hombres. La versión oficial del documento en inglés usa la expresión everybody, cuyo significado hace referencia a "personas" en oposición a "individuos" de la versión española. Como se afirmó, este uso de conceptos debe tenerse en cuenta para que la utilización 
de la Declaración, o de sus apartes, no se deje desviar por el sesgo biologicista, en perjuicio de un planteamiento más integral e integrador. No cabe duda de que el impacto de los contenidos del documento en tales políticas es verdaderamente notable. Hay decenas de documentos internacionales y nacionales que se apoyan en sus contenidos y que reflejan normas vinculantes. Las interpretaciones modernas y locales que descontextualizan y confrontan el sentido y la unidad del articulado, propician problemas bioéticos y actitudes contrarias al espíritu de la declaración, que frecuentemente ponen en peligro la dignidad humana, tales como la libertad de creencia y libertad de palabra como las aspiraciones más elevadas de la familia humana (cfr. Preámbulo de la Declaración). El ejemplo de la demanda contra el Estado costarricense por una pretendida "violación de los derechos "a la vida privada y familiar, del derecho a fundar una familia y del derecho a la igualdad y no discriminación”, manifiesta que una lectura inapropiada y descontextualizada del documento puede dar lugar a abusos directos contra seres humanos y su dignidad, en oposición al objetivo fundamental de la Carta. Si bien el documento señala la dignidad intrínseca y los derechos iguales e inalienables de todos los seres humanos sin distinción, no se explica cómo puede contradecirse la decisión del Estado de Costa Rica, cuando se opone a la fecundación in vitro como una manipulación de muchos seres humanos en estado embrional, con fines reproductivos. La circunstancia particular de la fecundación in vitro, ocurrida casi tres décadas después de la redacción del documento - y objeto de la demanda en la que se invoca a la Carta de 1948_- pone en evidencia la importancia de la explicitación de los postulados antropológicos del texto, los cuales se oponen a actos que contravengan la "dignidad intrínseca del ser humano" incluido, en este caso particular, del embrión, igualmente humano, merecedor del principal derecho: el derecho a la vida. Esta circunstancia vincula de forma radical el documento con el ejercicio de la Bioética y señala la pertinencia del mismo como otro fundamento para su propio ejercicio público, clínico, legislativo y de debate sobre este y otros temas semejantes.

A pesar del elevado significado y contenido antropológico, ético y bioético del texto, los investigadores constataron la ausencia de elementos que pudieran enriquecer el marco antropológico. Sin duda, el marco antropológico de la Declaración se puede robustecer de manera importante si, además de los contenidos antes señalados, se tienen en cuenta: la afectividad, la trascendencia, la intimidad, la espiritualidad, el amor, la corporalidad y la capacidad de dar sentido, pues son elementos antropológicos sustanciales que, sumados a los presentes en el documento, lo enriquecerían. Desde la perspectiva bioética, se reconoce que tales elementos debieron ser incluidos como parte fundamental del documento. Su omisión hace muy difícil tener una aproximación completa a la persona humana. Estos son factores que deberían estar presentes en cualquier cambio cultural que se refiera al desarrollo verdaderamente "humano". La Declaración goza de una notable unidad que le permite ser utilizada con fines de referencia jurídica, social, ética y política. No obstante, debe tenerse en cuenta que tomar artículos aislados o descontextualizados, para soportar pretensiones más o menos legítimas, solo puede llevar a desnaturalizar el documento y eventualmente a servirse de él como base — poco firme- para intereses y desarrollos posteriores. El conocimiento y aprecio por los derechos humanos es una herramienta de primer orden para preservar la humanidad y evitarle sufrimientos; para garantizar la paz, el verdadero desarrollo, la justicia y el progreso social. La cooperación internacional debería 
guiarse por estos derroteros que le dan vigor al bien común y lo sustentan como eje del cambio social.

América Latina tuvo un papel protagónico en la redacción de la Declaración, evitando que el documento se decantara por el individualismo o el colectivismo. Esta influencia debería ser retomada ahora para que las aplicaciones que se hacen de la Declaración y las legislaciones que se inspiran e instauran sobre ella, tengan en cuenta sus bases antropológicas y no se permita su contaminación con ideologías que privan al ser humano de su dignidad propia o, al menos, la lesionan.

La Bioética tiene mucho que agradecer a la Declaración y mucho por aportar en su aplicación, pues antes que la obligatoriedad legal está el foco potente del juicio ético, capaz de orientar la conducta humana para que sea adecuada al ser que la ejecuta.

\section{REFERENCIAS}

1. Organización de Naciones Unidas (ONU). Declaración Universal de Derechos Humanos. 1948. [Visitado 2014 jun 18]. Disponible en: http://www.un.org/es/documents/udhr/index_print.shtml

2. Comisión Interamericana de Derechos Humanos (OEA). Caso 12.361, Gretel Artavia Murillo y otros, "Fecundación In Vitro", Costa Rica. 2011. [Visitado 2014 Jun 18]. Disponible en: https://www.cidh.oas.org/demandas/12.361Esp.pdf.

3. República de Colombia. Código Civil. SF. Bogotá. [Visitado 2014 jun 18]. Disponible en: http://www.secretariasenado.gov. co/senado/basedoc/codigo/codigo_civil_pr003.html
4. República de Colombia, Corte Constitucional. Sentencia C-577 de 2011

5. Santander P. Por qué y cómo hacer análisis del discurso. Cinta Moebio. 2011;41:207-24.

6. van Dijik T. Discurso y Poder. Barcelona: Gedisa; 2009.

7. Fairclough N. Discourse and Social Change. 2006th ed. Malden; 1994

8. Discourse, social theory and social research: the discourse of welfare reformî. J Socioling. 4:163-95.

9. Habermas J. El concepto de dignidad humana y la utopía realista de los derechos humanos. Diánoia. 2010;55(64):3-25.

10. Macklin R. Dignity is a useless concept. BMJ Br Med Journal. 2003;327:1419-20

11. Requena P. Dignidad y auntonomía en la bioética norteamericana. Cuad Bioét. 2008;XIX:255-70.

12. León-Correa F. Bioética : la promoción de la dignidad de la persona en el ámbito biomédico. Madrid: Palabra; 2011.

13. Bonnin JE. Génesis política del discurso religioso. Iglesia y comunidad nacional (1981). Discurso Soc. 2012;6(4):850-4.

14. Foucault M. El orden del discurso. 3a ed. Barcelona: Tusquets; 1999

15. Aquino T. Suma Teológica. 2014 [Visitado 2015 May]. http:// biblioteca.campusdominicano.org/suma.htm.

16. Fairclough N. Discourse and social change. Cambridge: Cambridge Polity Press; 1992.

17. van Dijk T. Análisis del discurso ideológico. UAM. 1996; $6(\mathrm{X}): 15-43$. 